\title{
Comparison of surgical outcomes between isolated pancreaticojejunostomy, isolated gastrojejunostomy, and conventional pancreaticojejunostomy after pancreaticoduodenectomy: a systematic review and meta-analysis
}

Yunxiao Lyu* (D), Bin Wang, Yunxiao Cheng, Yueming Xu and Wei Bing Du

\begin{abstract}
Background: We aimed to compare the safety and effectiveness of the following procedures after pancreaticoduodenectomy: isolated pancreaticojejunostomy, isolated gastrojejunostomy, and conventional pancreaticojejunostomy.

Methods: We performed a systematic search of the following databases: PubMed, Embase, Web of Science, the Cochrane Central Register of Controlled Trials, and ClinicalTrials.gov until 1 January 2020. Pooled odds ratios (OR) or weighted mean differences (WMD) with 95\% confidence intervals (Cls) were calculated using STATA 12.0 statistical software.

Results: Thirteen studies involving 1942 patients were included in this study. Pooled analysis showed that reoperation rates following isolated pancreaticojejunostomy were lower reoperation than with conventional pancreaticojejunostomy ( $\mathrm{OR}=0.36,95 \% \mathrm{Cl}: 0.15-0.86, p=0.02$, respectively), and that isolated pancreaticojejunostomy required longer operation time vs conventional pancreaticojejunostomy (WMD $=43.61$, 95\% Cl: 21.64-65.58, $P=0.00$ ). Regarding postoperative pancreatic fistula, clinically-relevant postoperative pancreatic fistula, delayed gastric emptying, clinically-relevant delayed gastric emptying, bile leakage, hemorrhage, reoperation, length of postoperative hospital stay, major complications, overall complications, and mortality, we found no significant differences for either isolated pancreaticojejunostomy versus conventional pancreaticojejunostomy or isolated gastrojejunostomy versus conventional pancreaticojejunostomy.
\end{abstract}

Conclusions: This study showed that isolated pancreaticojejunostomy was associated with a lower reoperation rate, but required longer operation time vs conventional pancreaticojejunostomy. Considering the limitations, highquality randomized controlled trials are required.

Keywords: Isolated Pancreaticoduodenectomy, Pancreaticojejunostomy, Gastrojejunostomy, Meta-analysis

\footnotetext{
* Correspondence: Ivyunxiao1986@gmail.com

Department of Hepatobiliary Surgery, Wenzhou Medical University Affiliated Dongyang Hospital, 60 West Wuning Road, Dongyang 322100, Zhejiang Province, China
}

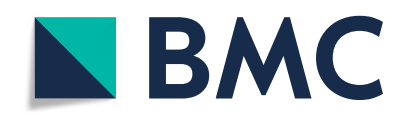

( ) The Author(s). 2020 Open Access This article is licensed under a Creative Commons Attribution 4.0 International License, which permits use, sharing, adaptation, distribution and reproduction in any medium or format, as long as you give appropriate credit to the original author(s) and the source, provide a link to the Creative Commons licence, and indicate if changes were made. The images or other third party material in this article are included in the article's Creative Commons licence, unless indicated otherwise in a credit line to the material. If material is not included in the article's Creative Commons licence and your intended use is not permitted by statutory regulation or exceeds the permitted use, you will need to obtain permission directly from the copyright holder. To view a copy of this licence, visit http://creativecommons.org/licenses/by/4.0/ The Creative Commons Public Domain Dedication waiver (http://creativecommons.org/publicdomain/zero/1.0/) applies to the data made available in this article, unless otherwise stated in a credit line to the data. 


\section{Background}

Pancreaticoduodenectomy, one of the most complex intra-abdominal operations, is widely used for benign and malignant disease located in the pancreatic head or periampullary region [1, 2]. Despite developments in surgical techniques, pancreaticoduodenectomy is still accompanied by a high postoperative complication rate of 40-50\% [3]. Previous studies demonstrated that the most common complications after pancreaticoduodenectomy were postoperative pancreatic fistula (POPF) and delayed gastric emptying (DGE) [3, 4]. Several methods of digestive tract reconstruction have been recommended to reduce the main postoperative complications, namely conventional pancreaticojejunostomy, isolated pancreaticojejunostomy $[5,6]$, and isolated gastrojejunostomy $[7,8]$. Isolated pancreaticojejunostomy, first described in 1976, was proposed to reduce complications such as POPF, based on the theory of separating bile and pancreatic enzymes [5]. In isolated gastrojejunostomy, a second loop is made to perform the gastroenteric anastomosis, which may favor digestive transit by separating the pancreatic enzymes and gastric sutures [9]. However, the debate regarding these three reconstructions is on-going. Some studies demonstrated that isolated pancreaticojejunostomy and isolated gastrojejunostomy may be associated with less postoperative complications, such as POPF [10] and DGE [11]. Kaman et al. suggested that morbidity and mortality could be reduced using isolated pancreaticojejunostomy to separate the bile from pancreatic secretions [12]; however, other studies reached different conclusions. Furthermore, studies comparing isolated pancreaticojejunostomy versus conventional pancreaticojejunostomy and isolated gastrojejunostomy versus conventional pancreaticojejunostomy involved low numbers of patients or had retrospective designs. With the recent publication of several new studies, we performed this systematic review and meta-analysis to compare the surgical outcomes of isolated pancreaticojejunostomy, isolated gastrojejunostomy, and conventional pancreaticojejunostomy.

\section{Methods}

\section{Search strategy}

We performed a systematic review and meta-analysis according to the Preferred Reporting Items for Systematic Reviews and Meta-Analysis (PRISMA) statement. Two authors independently searched the electronic databases of PubMed, Embase, Web of Science, Cochrane Central Register of Controlled Trials (CENTRAL), and ClinicalTrials.gov. Published trials comparing the efficacy and safety of isolated pancreaticojejunostomy, isolated gastrojejunostomy, and conventional pancreaticojejunostomy after pancreaticoduodenectomy were evaluated in this study. We used the following English search terms: "pancreaticoduodenectomy," "pancreatoduodenectomy," "Whipple," "pylorus-preserving pancreaticoduodenectomy," "pancreaticojejunostomy," "Rou-en-Y," and "isolated Roux loop gastrojejunostomy." The search was restricted to human subjects, available full text, and Englishlanguage articles. The references of the articles identified after the initial search were also manually reviewed.

\section{Inclusion and exclusion criteria}

Studies were included based on the following criteria: (1) trials had to compare isolated pancreaticojejunostomy or isolated gastrojejunostomy versus conventional pancreaticojejunostomy in patients undergoing pancreaticoduodenectomy or pylorus-preserving pancreaticoduodenectomy; and (2) complete data were provided in English with available full text. Reviews, conference abstracts, and studies with unavailable full text were excluded.

\section{Outcome measures}

The analyzed outcome measures were POPF, clinicallyrelevant POPF (CR-POPF), DGE, clinically-relevant DGE (CR-DGE), operation time, bile leakage, hemorrhage, reoperation, length of postoperative hospital stay, major complications, overall complications, and mortality. The definition of POPF, CR-POPF, DGE and CR-DGE was according to the criteria of International Study Group for Pancreatic Surgery (ISGPS) [13, 14]. Major complications were defined as Clavin-Dindo grade $\geq$ IIIa [15]. Isolated pancreaticojejunostomy was created to prevent pancreatic fistula by separating pancreatic juice from bile juice after pancreaticoduodenectomy. Isolated gastrojejunostomy was created to prevent delayed gastric emptying after pancreaticoduodenectomy. Then, subgroup analyses were conducted depending on the different construction method.

\section{Data extraction and quality assessment}

Data extraction was performed by two independent authors using a standardized selection form that included the first author, year of publication, type of study, country in which the study was performed, type of reconstruction, and general data. Conflicts in data abstraction were resolved by consensus and by referring to the original article. EndNote version X8 (Thomson Reuters, Toronto, ON, Canada) was used to remove duplicate studies. The methodological quality of all included studies was assessed using the validated Newcastle-Ottawa scale [16]. Studies scoring $>7$ were considered of high quality.

\section{Statistical analysis}

All statistical analyses were performed using STATA/SE 12.0 (Stata Corp., College Station, TX, USA). We used odds ratios (OR) with 95\% confidence intervals (CIs) for dichotomous outcomes, and weighted mean difference 
(WMD) with 95\% CIs for continuous variables. A twotailed $p$ value $<0.05$ was considered statistically significant. Heterogeneity among studies was evaluated using the $x^{2}$ test; values $<25,25-50$, and $>50$ were classified as low, moderate, and high heterogeneity, respectively, and were treated as binary data. We created funnel plots and performed Egger's test [17] to evaluate the risk of publication bias. Sensitivity analyses were performed by removing individual studies from the data set and analyzing the effect on the overall results, to identify sources of signficant heterogeneity. This type of analysis is called "Jackknife analysis", named by John Tukey, which can improvise a solution for a variety of problems [18].

\section{Results}

\section{Study selection and trial characteristics}

According to the search strategy, we identified 1563 studies. Of these, 420 duplicate articles were excluded, and we retrieved the remaining 1143 studies based on their titles and abstracts. After excluding irrelevant articles for various reasons, we included a final 14 trials involving a total of 2043 patients [6, 9-12, 19-27]. A flowchart of the literature search process is shown in
Fig. 1, and the characteristics and quality evaluation of the included studies are shown in Table 1. There were four randomized controlled trials (RCTs), one prospective study, and eight retrospective studies. The isolated pancreaticojejunostomy group comprised 482 patients, the isolated gastrojejunostomy group comprised $92 \mathrm{pa}-$ tients, and the isolated pancreaticojejunostomy + gastrojejunostomy group comprised 112 patients. The sample sizes among the studies ranged from 40 to 700 patients.

\section{Meta-analysis \\ POPF}

Twelve studies provided data regarding POPF, with 908 patients in the isolated pancreaticojejunostomy versus conventional pancreaticojejunostomy group, 259 patients in the isolated gastrojejunostomy versus conventional pancreaticojejunostomy group, and 700 patients in the isolated pancreaticojejunostomy + gastrojejunostomy group versus the conventional pancreaticojejunostomy group. Regarding POPF, we found no significant difference between isolated pancreaticojejunostomy and conventional pancreaticojejunostomy $(\mathrm{OR}=0.83,95 \% \mathrm{CI}$ : $0.58-1.18 ; \quad P=0.29$ ) (Fig. 2a) or between isolated

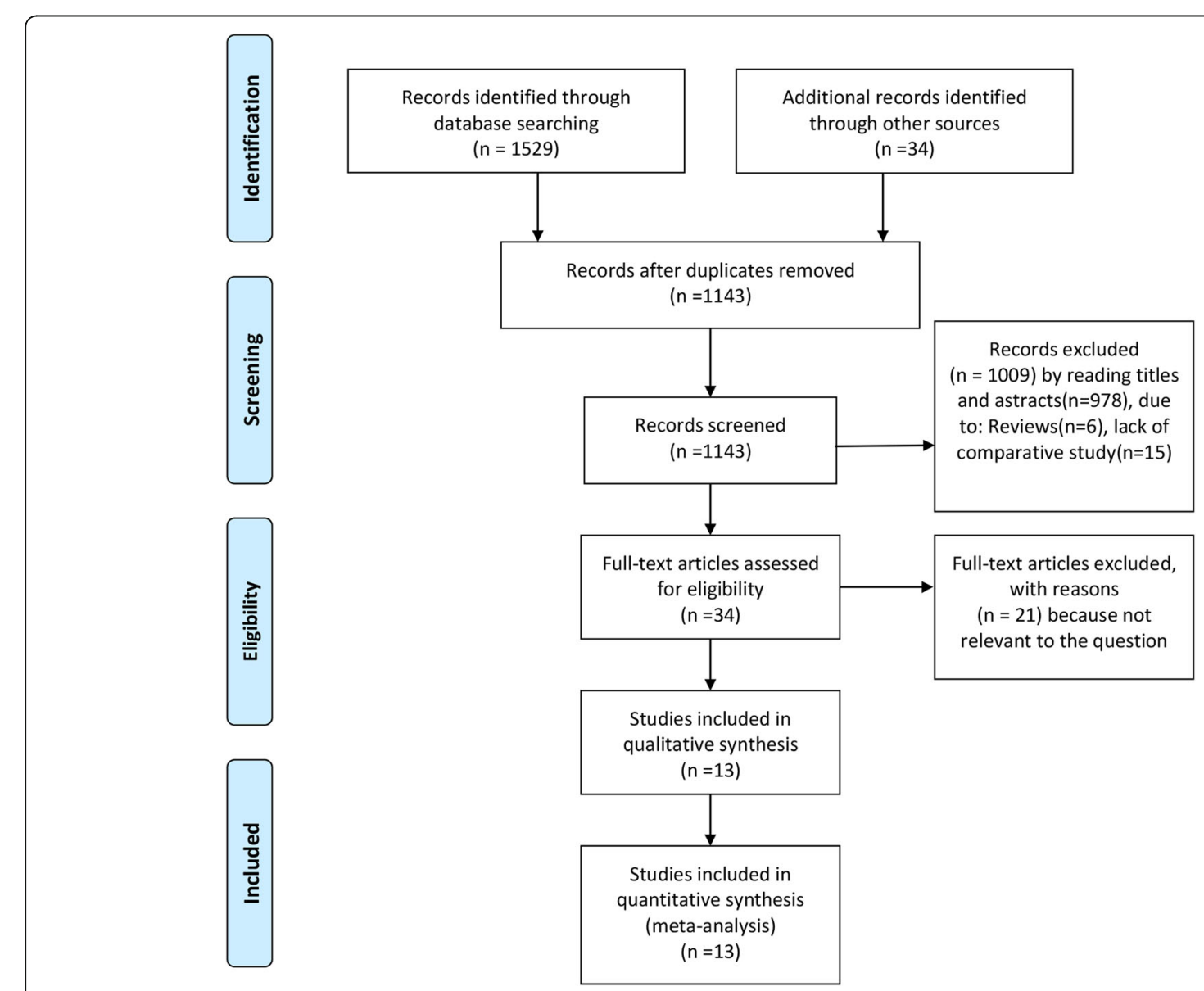

Fig. 1 Flow diagram of the published articles evaluated for inclusion in this meta-analysis 
Table 1 Characteristic of the included trials

\begin{tabular}{|c|c|c|c|c|c|c|c|c|c|}
\hline First author & Year & Country & Design & Intervention & $N$ & Age & $\begin{array}{l}\text { Gender } \\
\text { (Male/Female) }\end{array}$ & PD/PPPD & NOS \\
\hline Aghalarov & 2018 & Germany & Retro & $\begin{array}{l}\text { Isolated PJ } \\
\text { Conventional PJ }\end{array}$ & $\begin{array}{l}25 \\
50\end{array}$ & $\begin{array}{l}65 \pm 11 \\
64 \pm 11\end{array}$ & $\begin{array}{l}10 / 15 \\
17 / 33\end{array}$ & $\begin{array}{l}5 / 20 \\
6 / 44\end{array}$ & 7 \\
\hline Ballas & 2010 & Greece & Retro & $\begin{array}{l}\text { Isolated PJ } \\
\text { Conventional PJ }\end{array}$ & $\begin{array}{l}46 \\
42\end{array}$ & $\begin{array}{l}64.4 \pm 9.5 \\
60.9 \pm 11.5\end{array}$ & $\begin{array}{l}29 / 17 \\
23 / 19\end{array}$ & $\begin{array}{l}38 / 8 \\
25 / 17\end{array}$ & 7 \\
\hline Ben-Ishay & 2019 & Israel & Retro & $\begin{array}{l}\text { Isolated GJ } \\
\text { Conventional PJ }\end{array}$ & $\begin{array}{l}52 \\
127\end{array}$ & $\begin{array}{l}68.2 \pm 9.6 \\
68 \pm 13.7\end{array}$ & $\begin{array}{l}26 / 26 \\
62 / 65\end{array}$ & $\begin{array}{l}52 / 0 \\
127 / 0\end{array}$ & 8 \\
\hline Busquets & 2018 & Spain & RCT & $\begin{array}{l}\text { Isolated GJ } \\
\text { Conventional PJ }\end{array}$ & $\begin{array}{l}40 \\
40\end{array}$ & $\begin{array}{l}68.1 \pm 11.7) \\
65.6 \pm 10.9)\end{array}$ & $\begin{array}{l}24 / 16 \\
24 / 16\end{array}$ & $\begin{array}{l}40 / 0 \\
40 / 0\end{array}$ & 9 \\
\hline Casadei & 2008 & Italy & Pro & $\begin{array}{l}\text { Isolated PJ } \\
\text { Conventional PJ }\end{array}$ & $\begin{array}{l}18 \\
20\end{array}$ & $\begin{array}{l}65.7 \pm 10.0 \\
56.3 \pm 11.0\end{array}$ & $\begin{array}{l}11 / 7 \\
13 / 7\end{array}$ & $\begin{array}{l}14 / 4 \\
11 / 9\end{array}$ & 8 \\
\hline Chhaida & 2018 & Tunisia & Retro & $\begin{array}{l}\text { Isolated PJ } \\
\text { Conventional PJ }\end{array}$ & $\begin{array}{l}35 \\
35\end{array}$ & $\begin{array}{l}61(44-74) \\
61(44-74)\end{array}$ & $\begin{array}{l}12,23 \\
12,23\end{array}$ & $\begin{array}{l}35 / 0 \\
35 / 0\end{array}$ & 7 \\
\hline EL-SOROGY & 2016 & Egypt & RCT & $\begin{array}{l}\text { Isolated PJ } \\
\text { Conventional PJ }\end{array}$ & $\begin{array}{l}20 \\
20\end{array}$ & $\begin{array}{l}53(29-66) \\
56(34-73)\end{array}$ & $\begin{array}{l}10 / 10 \\
16 / 4\end{array}$ & $\begin{array}{l}0 / 20 \\
0 / 20\end{array}$ & 7 \\
\hline Grobmyer & 2008 & USA & Retro & $\begin{array}{l}\text { Isolated PJ + GJ } \\
\text { Conventional PJ }\end{array}$ & $\begin{array}{l}112 \\
588\end{array}$ & $\begin{array}{l}68(36-83) \\
70(38-90)\end{array}$ & $\begin{array}{l}70 / 42 \\
288 / 300\end{array}$ & $\begin{array}{l}112 / 0 \\
588 / 0\end{array}$ & 8 \\
\hline Kaman & 2008 & India & Retro & $\begin{array}{l}\text { Isolated PJ } \\
\text { Conventional PJ }\end{array}$ & $\begin{array}{l}60 \\
51\end{array}$ & $\begin{array}{l}51 \pm 13.3 \\
50 \pm 13.6\end{array}$ & $\begin{array}{l}39 / 21 \\
35 / 16\end{array}$ & $\begin{array}{l}60 / 0 \\
42 / 9\end{array}$ & 8 \\
\hline Ke & 2013 & China & RCT & $\begin{array}{l}\text { Isolated PJ } \\
\text { Conventional PJ }\end{array}$ & $\begin{array}{l}107 \\
109\end{array}$ & $\begin{array}{l}58.3 \pm 5.9 \\
59.3 \pm 6.6\end{array}$ & $\begin{array}{l}51 / 56 \\
50 / 59\end{array}$ & $\begin{array}{l}107 / 0 \\
109 / 0\end{array}$ & 8 \\
\hline Li & 2015 & China & Retro & $\begin{array}{l}\text { Isolated PJ } \\
\text { Conventional PJ }\end{array}$ & $\begin{array}{l}43 \\
43\end{array}$ & $\begin{array}{l}54.2 \pm 9.6 \\
53.8 \pm 10.2\end{array}$ & $\begin{array}{l}27 / 16 \\
27 / 16\end{array}$ & $\begin{array}{l}12 / 31 \\
10 / 33\end{array}$ & 7 \\
\hline Perwaiz & 2006 & India & Retro & $\begin{array}{l}\text { Isolated PJ } \\
\text { Conventional PJ }\end{array}$ & $\begin{array}{l}53 \\
55\end{array}$ & $\begin{array}{l}53.3 \pm 12.1 \\
53.5 \pm 10.1\end{array}$ & $\begin{array}{l}40 / 13 \\
41 / 14\end{array}$ & $\begin{array}{l}53 / 0 \\
53 / 0\end{array}$ & 7 \\
\hline Shimoda & 2013 & Japan & RCT & $\begin{array}{l}\text { Isolated GJ } \\
\text { Conventional PJ }\end{array}$ & $\begin{array}{l}49 \\
52\end{array}$ & $\begin{array}{l}65.7 \pm 11.1 \\
66.5 \pm 9.8\end{array}$ & $\begin{array}{l}28 / 21 \\
32 / 20\end{array}$ & $\begin{array}{l}49 / 0 \\
52 / 0\end{array}$ & 8 \\
\hline Tani & 2014 & Japan & RCT & $\begin{array}{l}\text { Isolated PJ } \\
\text { Conventional PJ }\end{array}$ & $\begin{array}{l}75 \\
76\end{array}$ & $\begin{array}{l}69.6 \pm 7.9 \\
68.0 \pm 8.9\end{array}$ & $\begin{array}{l}39 / 36 \\
42 / 34\end{array}$ & $\begin{array}{l}2 / 73 \\
7 / 70\end{array}$ & 8 \\
\hline
\end{tabular}

Retro retrospective, Pro prospective, $R C T$ randomized controlled trial, $P J$ pancreaticojejunostomy, GJ Gastrojejunostomy, $P D$ pancreaticoduodenectomy, $P P P D$ pylorus preserving pancreaticoduodenectomy

gastrojejunostomy and conventional pancreaticojejunostomy $(\mathrm{OR}=0.78,95 \% \mathrm{CI}$ : 0.42-1.42; $P=0.41)$ (Fig. 2a). One study evaluating isolated pancreaticojejunostomy + gastrojejunostomy performed by Grobmyer et al. showed that conventional pancreaticojejunostomy was associated with lower rates of POPF vs isolated pancreaticojejunostomy + gastrojejunostomy $(\mathrm{OR}=2.90$, 95\% CI: $1.53-$ 5.48; $P=0.001$ ) (Fig. 2a).

\section{Cr-POPF}

Twelve studies provided data for the incidence of CRPOPF, with 983 patients in the isolated pancreaticojejunostomy versus conventional pancreaticojejunostomy group, and 259 patients in the isolated gastrojejunostomy versus conventional pancreaticojejunostomy group. Our meta-analysis revealed no significant difference regarding the incidence of CR-POPF between isolated pancreaticojejunostomy and conventional pancreaticojejunostomy ( $\mathrm{OR}=0.70,95 \% \mathrm{CI}: 0.35-1.42 ; P=0.32$ ) or between isolated gastrojejunostomy and conventional pancreaticojejunostomy (OR $=0.81,95 \% \mathrm{CI}$ : $0.23-2.90 ; P=0.74)$ (Fig. $2 \mathrm{~b})$.
DGE

Thirteen studies provided data for the incidence of DGE, with 908 patients in the isolated pancreaticojejunostomy versus conventional pancreaticojejunostomy group, 259 patients in the isolated gastrojejunostomy versus conventional pancreaticojejunostomy group, and 80 patients in the isolated pancreaticojejunostomy + gastrojejunostomy versus conventional pancreaticojejunostomy group. We found no significant differences regarding DGE when comparing isolated pancreaticojejunostomy versus conventional pancreaticojejunostomy $(\mathrm{OR}=1.10,95 \% \mathrm{CI}$ : $0.76-1.58 ; P=0.62)$, isolated gastrojejunostomy versus conventional pancreaticojejunostomy $(\mathrm{OR}=035,95 \% \mathrm{CI}$ : $0.11-5.20 ; P=0.78$ ), or pancreaticojejunostomy + gastrojejunostomy versus conventional pancreaticojejunostomy $(\mathrm{OR}=0.99,95 \%$ CI: $0.50-1.95 ; P=0.96)$ (Fig. 2c).

\section{Cr-DGE}

Four studies provided data for the incidence of CR-DGE, with 239 patients in the isolated pancreaticojejunostomy versus conventional pancreaticojejunostomy group and 259 patients in the isolated gastrojejunostomy versus 


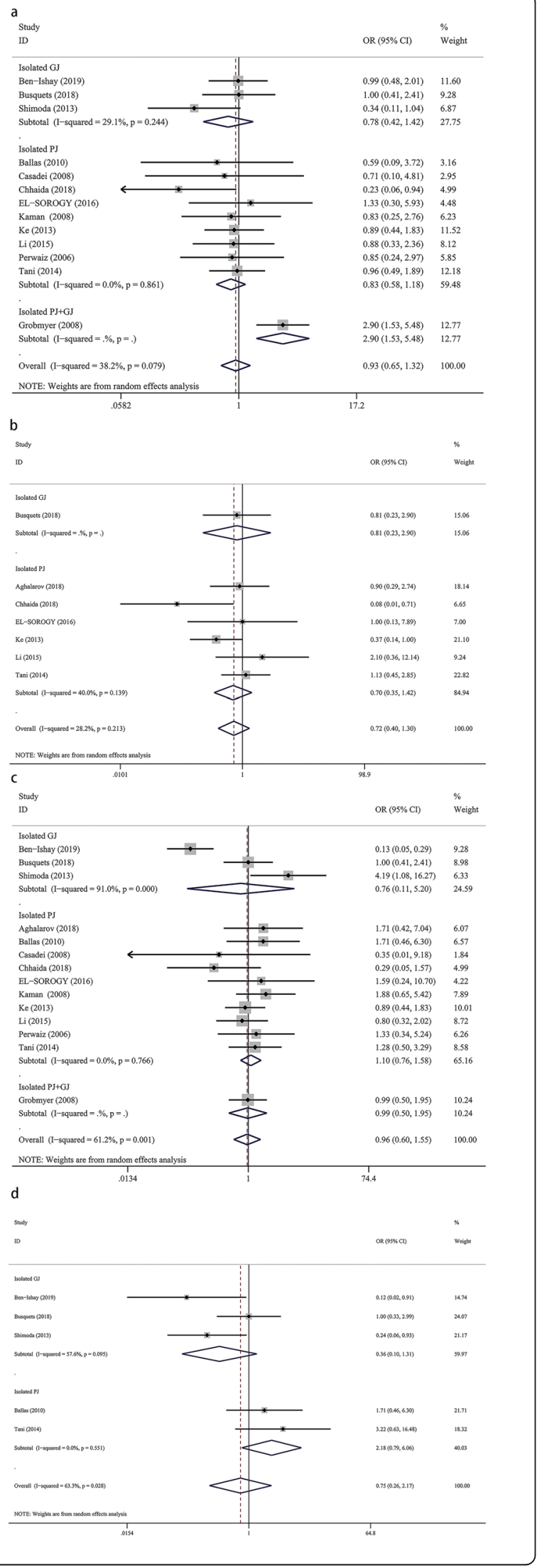

Fig. 2 Forest plot of the meta-analysis comparing isolated pancreaticojejunostomy, isolated gastrojejunostomy, and conventional pancreaticojejunostomy regarding (a) postoperative pancreatic fistula, (b) clinically-relevant postoperative pancreatic fistula, (c) delayed gastric emptying, and (d) clinically-relevant delayed gastric emptying

conventional pancreaticojejunostomy group. We found no significant differences for CR-DGE between isolated pancreaticojejunostomy and conventional pancreaticojejunostomy $(\mathrm{OR}=2.18,95 \% \mathrm{CI}$ : $0.79-6.06 ; P=0.13$ ) or between isolated gastrojejunostomy and conventional pancreaticojejunostomy $(\mathrm{OR}=0.36,95 \% \mathrm{CI}: 0.10-1.31$; $P=0.12)$ (Fig. 2d).

\section{Bile leakage}

Eleven studies provided data for the incidence of bile leakage, with 945 patients in the isolated pancreaticojejunostomy versus conventional pancreaticojejunostomy group and 259 patients in the isolated gastrojejunostomy versus conventional pancreaticojejunostomy group. We found no significant difference for the incidence of bile leakage between isolated pancreaticojejunostomy and conventional pancreaticojejunostomy $(\mathrm{OR}=0.68,95 \%$ CI: $0.27-1.69 ; P=0.40)$ or between isolated gastrojejunostomy and conventional pancreaticojejunostomy $(\mathrm{OR}=0.67,95 \% \mathrm{CI}: 0.28-1.63 ; P=0.38)$ (Fig. 3a).

\section{Hemorrhage}

Nine studies provided data for the incidence of hemorrhage, with 228 patients in the isolated pancreaticojejunostomy versus conventional pancreaticojejunostomy group and 80 patients in the isolated gastrojejunostomy versus conventional pancreaticojejunostomy group. We found no significant difference regarding the incidence of hemorrhage between isolated pancreaticojejunostomy and conventional pancreaticojejunostomy $(\mathrm{OR}=0.77,95 \% \mathrm{CI}$ : $0.38-1.57 ; P=0.47$ ) or between isolated gastrojejunostomy and conventional pancreaticojejunostomy ( $\mathrm{OR}=0.57,95 \%$ CI: $0.13-2.55 ; P=0.46$ ) (Fig. 3b).

\section{Reoperation}

Nine studies provided data for the reoperation rate, with 659 patients in the isolated pancreaticojejunostomy versus conventional pancreaticojejunostomy group and 80 patients in the isolated gastrojejunostomy versus conventional pancreaticojejunostomy group. We found that isolated pancreaticojejunostomy was associated with a lower reoperation rate versus conventional pancreaticojejunostomy $(\mathrm{OR}=0.36,95 \% \mathrm{CI}: 0.15-0.86 ; p=0.02)$, but there was no significant difference between isolated gastrojejunostomy and conventional pancreaticojejunostomy $(\mathrm{OR}=0.65,95 \% \mathrm{CI}$ : $0.10-4.11 ; P=0.65)$ (Fig. $3 \mathrm{c}$ ). 


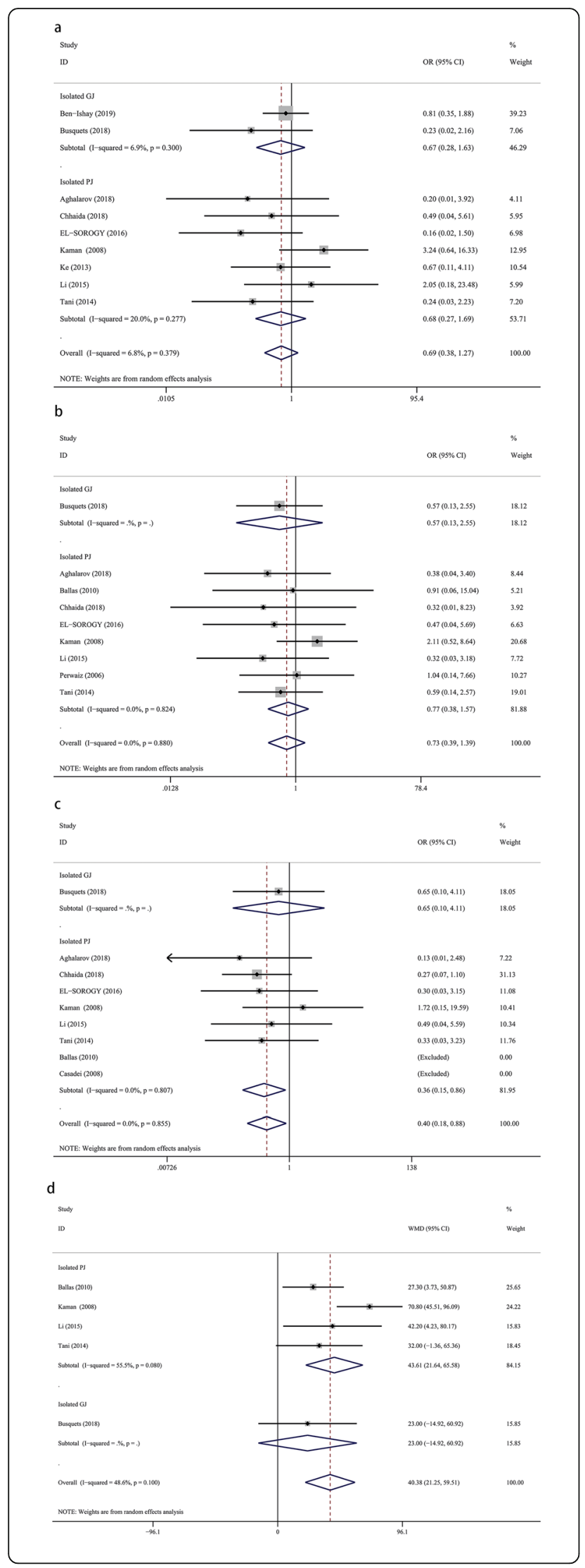

Fig. 3 Forest plot of the meta-analysis comparing isolated pancreaticojejunostomy, isolated gastrojejunostomy, and conventional pancreaticojejunostomy regarding (a) bile leakage, (b) hemorrhage, (c) reoperation, and (d) operation time

\section{Operation time}

Four studies provided data for operation time, with 436 patients in the isolated pancreaticojejunostomy versus conventional pancreaticojejunostomy group and 80 patients in the isolated gastrojejunostomy versus conventional pancreaticojejunostomy group. Our results showed that conventional pancreaticojejunostomy was associated with shorter operation times versus isolated pancreaticojejunostomy (WMD = 43.61, 95\% CI: 21.64-65.58; $P=0.00$ ); however, there was no significant difference between isolated gastrojejunostomy and conventional pancreaticojejunostomy ( $\mathrm{WMD}=23.00$, 95\% CI: - 14.92-60.92; $P=0.23$ ) (Fig. 3d).

\section{Postoperative hospital stay}

Six studies provided data for the length of postoperative hospital stay, with 659 patients in the isolated pancreaticojejunostomy versus conventional pancreaticojejunostomy group and 80 patients in the isolated gastrojejunostomy versus conventional pancreaticojejunostomy group. We found no significant difference for postoperative hospital stay between isolated pancreaticojejunostomy and conventional pancreaticojejunostomy (WMD $=-2.01,95 \% \mathrm{CI}$ : $-5.66-$ $1.65 ; P=0.53$ ) or between isolated gastrojejunostomy and conventional pancreaticojejunostomy (WMD $=3.67,95 \%$ CI: $-7.89-15.22 ; P=0.28$ ) (Fig. 4a).

\section{Major complications}

Three studies provided data describing major complications, with 195 patients in the isolated pancreaticojejunostomy versus conventional pancreaticojejunostomy group and 80 patients in the isolated gastrojejunostomy versus conventional pancreaticojejunostomy group. Our results showed that isolated pancreaticojejunostomy was associated with lightly fewer major complications versus conventional pancreaticojejunostomy $(\mathrm{OR}=0.34,95 \%$ CI: $0.11-1.03 ; P=0.05)$, but there was no significant difference between isolated gastrojejunostomy and conventional pancreaticojejunostomy $(\mathrm{OR}=1.00$, 95\% CI: $0.35-$ 2.86; $P=1.00)$ (Fig. 4b).

\section{Overall complications}

Twelve studies provided data describing the overall complications rate, with 983 patients in the isolated pancreaticojejunostomy versus conventional pancreaticojejunostomy group and 259 patients in the isolated gastrojejunostomy versus conventional pancreaticojejunostomy group. Our meta-analysis revealed no significant difference between isolated pancreaticojejunostomy and conventional pancreaticojejunostomy (OR $=1.08,95 \% \mathrm{CI}$ : $0.83-1.40 ; P=0.56)$ or 


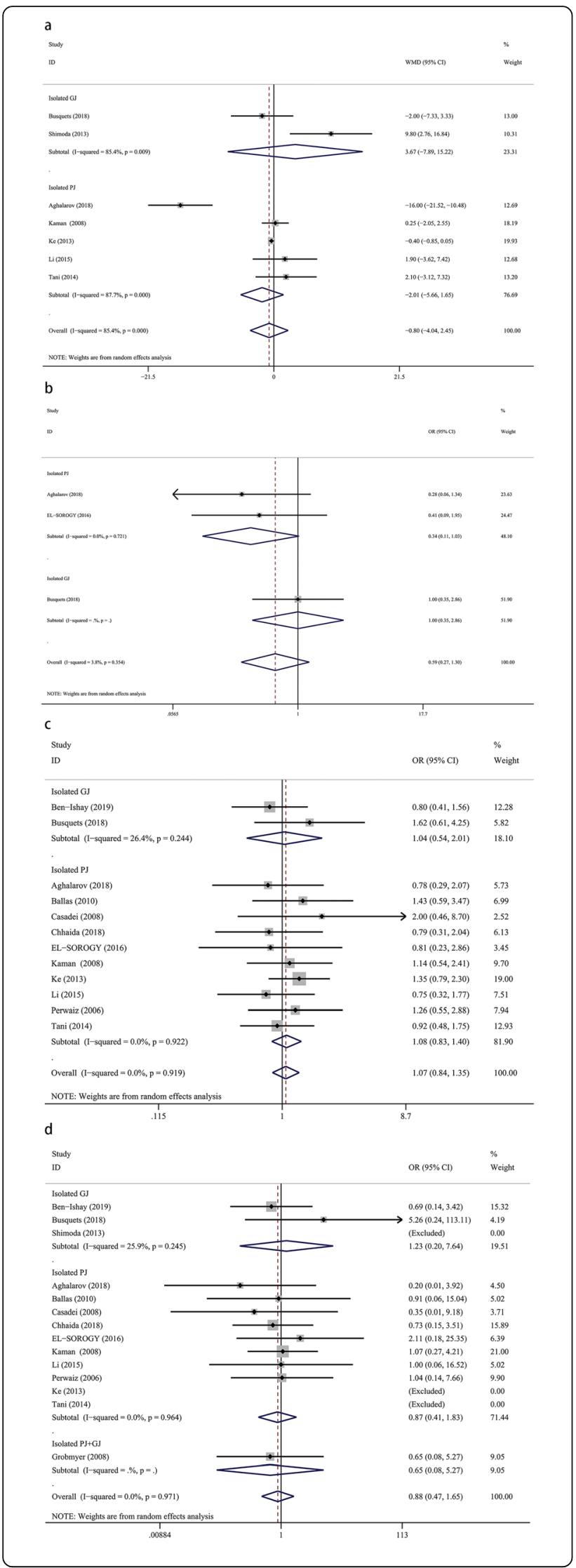

Fig. 4 Forest plot of the meta-analysis comparing isolated pancreaticojejunostomy, isolated gastrojejunostomy, and conventional pancreaticojejunostomy regarding (a) length of postoperative hospital stay, (b) major complications, (c) overall complications, and (d) mortality

between isolated gastrojejunostomy and conventional pancreaticojejunostomy $(\mathrm{OR}=1.04,95 \% \mathrm{CI}: 0.54-2.01 ; P=$ 0.91) (Fig. 4c).

\section{Mortality}

Thirteen studies provided data for mortality rates, with 983 patients in the isolated pancreaticojejunostomy versus conventional pancreaticojejunostomy group, 259 patients in the isolated gastrojejunostomy versus conventional pancreaticojejunostomy group, and 700 patients in the isolated pancreaticojejunostomy + gastrojejunostomy versus conventional pancreaticojejunostomy group. We found no significant difference in mortality rates between isolated pancreaticojejunostomy and conventional pancreaticojejunostomy ( $\mathrm{OR}=0.87,95 \% \mathrm{CI}: 0.41-1.83 ; P=0.71)$, between isolated gastrojejunostomy and conventional pancreaticojejunostomy ( $\mathrm{OR}=1.23,95 \% \mathrm{CI}: 0.20-7.64 ; P=0.82)$, or between isolated pancreaticojejunostomy + gastrojejunostomy versus conventional pancreaticojejunostomy $(\mathrm{OR}=0.65$, 95\% CI: 0.08-5.27; $p=0.69$ ) (Fig. 4d).

\section{Publication bias and sensitivity analysis}

The funnel plots for the parameters were symmetrical, and Egger's test revealed no significant publication bias. Sensitivity analyses were performed by removing individual studies from the data and analyzing the effect on the overall results. However, these exclusions did not alter the results.

\section{Discussion}

This meta-analysis compared isolated pancreaticojejunostomy and isolated gastrojejunostomy with conventional pancreaticojejunostomy after pancreaticoduodenectomy. Our results showed that isolated pancreaticojejunostomy was associated with fewer major complications and lower reoperation rates, but required longer operation time versus conventional pancreaticojejunostomy. However, the rates for overall complications, POPF, CR-POPF, DGE, CR-DGE, bile leakage, and hemorrhage, and the length of postoperative hospital stay and mortality rates with isolated pancreaticojejunostomy versus isolated gastrojejunostomy were similar to rates for conventional pancreaticojejunostomy. Considering the limitations, future high-quality RCTs are required.

POPF, one of the most frequent complications after pancreaticoduodenectomy, is associated with intra-abdominal abscess, sepsis, and life-threatening hemorrhage. Many methods have been used to decrease the incidence of POPF such as using fibrin [28] or pancreatic stenting [29], and 
modifying the jejunal anastomosis [30]; however, the optimal technique is still debated. Our study revealed no significant difference between isolated pancreaticojejunostomy and conventional pancreaticojejunostomy, which was consistent with most previous studies. However, some studies demonstrated that isolated pancreaticojejunostomy was associated with lower rates of POPF after pancreaticoduodenectomy compared with conventional pancreaticojejunostomy [20,31]. Several reasons were revealed in these studies, including the separation of bile acids and pancreatic enzymes [5] and decreasing the reflux of bile into the pancreas [32]; however, these advantages were theoretical, and comparative studies are lacking. Of note, adding jejunojejunal anastomosis in isolated pancreaticojejunostomy could increase intestinal intraluminal pressure, which may affect the pancreaticojejunostomy anastomosis [19]. An RCT performed by Ke et al. showed that the rate of Grade B POPF in the isolated pancreaticojejunostomy group was higher than that in the conventional pancreaticojejunostomy group [6]. In addition to the 13 studies involving 1942 patients, our study showed that isolated pancreaticojejunostomy provides no advantage over conventional pancreaticojejunostomy regarding CR-POPF. Similar to previous studies evaluating isolated gastrojejunostomy, the incidences of POPF and CR-POPF were similar to those with conventional pancreaticojejunostomy.

DGE is also one of the most frequent complications after pancreaticoduodenectomy, with rates ranging from 13.5 to $40 \%$ [14, 33]. Several surgical reconstruction procedures have been proposed to decrease the incidence of DGE, namely the Billroth I procedure, Braun enteroenterostomy, and isolated gastrojejunostomy. However, few studies have compared isolated gastrojejunostomy and conventional pancreaticojejunostomy. The debate regarding isolated gastrojejunostomy versus conventional pancreaticojejunostomy is on-going. Regarding DGE and CR-DGE, our results revealed no significant difference between isolated gastrojejunostomy and conventional pancreaticojejunostomy, and we found similar results when comparing isolated pancreaticojejunostomy and conventional pancreaticojejunostomy. A previous metaanalysis involving three studies revealed that conventional pancreaticojejunostomy was associated with lower rates of DGE versus isolated gastrojejunostomy [34]; however, the sample size in the study was small. In the current meta-analysis, we showed that the incidences of DGE and CR-DGE were similar for both isolated pancreaticojejunostomy and conventional pancreaticojejunostomy, indicating that the activation of pancreatic enzymes does not influence the occurrence of DGE.

Regarding major complications, our meta-analysis demonstrated that isolated pancreaticojejunostomy has comparable with conventional pancreaticojejunostomy. The definition of major complications in our included studies varied. Applied with Clavin-Dindo grade, there were three studies provided the data of major complications. Our study showed that there was no significantly difference between isolated pancreaticojejunostomy and conventional pancreaticojejunostomy. Interestingly, isolated pancreaticojejunostomy decreases the incidence of reoperation in this study. The study conducted by Aghalarov et al and Chhaidar et al showed that isolated pancreaticojejunostomy has less reoperation $[10,20]$. They showed that the reoperation was largely because of POPF-related complications. Nevertheless, there are many factors that affect the occurrence of reoperation after surgery, such as bleeding, gastrointestinal anastomotic leakage. Additionally, with the development of percutaneous drainage and other procedures, there was fewer reoperation. However, there was lack of enough data about the detail of reoperations which may lead to bias in this present study.

\section{Conclusion}

In conclusion, isolated pancreaticojejunostomy was associated with lower reoperation rates, but required longer operation times versus conventional pancreaticojejunostomy. The rate of major complications, overall complications, POPF, CR-POPF, DGE, CR-DGE, bile leakage, and hemorrhage, and the length of postoperative hospital stay and mortality rates with isolated pancreaticojejunostomy and isolated gastrojejunostomy were similar to the respective rates with conventional pancreaticojejunostomy. However, further randomized controlled trials are needed.

\section{Abbreviations}

POPF: Postoperative pancreatic fistula; DGE: Delayed gastric emptying; $\mathrm{Cl}$ : Confidence interval; OR: Odds ratios; WMD: Weighted mean difference; RCTs: Randomized controlled trials

\section{Acknowledgments}

We thank Jane Charbonneau, DVM, from Liwen Bianji, Edanz Group China (www.liwenbianji.cn/ac), for editing the English text of a draft of this manuscript.

\section{Authors' contributions}

Conception and design: YXL. Data collection: YXC, BW. Quality assessment: YMX, WBD. Final approval of studies: YXL. Statistical analysis: YXL, YXC. Article writing: YXL, BW. All authors have read and approved the manuscript.

\section{Funding}

The authors received no financial support for the research, authorship, and/ or publication of this article.

Availability of data and materials

All the data used in the study can be obtained from the original articles.

Ethics approval and consent to participate

Not applicable.

Consent for publication

Not applicable. 


\section{Competing interests}

Yunxiao Lyu*, Bin Wang, Yunxiao Cheng, Yueming Xu and WeiBing Du have no conflicts of interest or financial ties to disclose.

Received: 11 March 2020 Accepted: 7 August 2020

Published online: 20 August 2020

\section{References}

1. Butturini G, Marcucci S, Molinari E, Mascetta G, Landoni L, Crippa S, Bassi C. Complications after pancreaticoduodenectomy: the problem of current definitions. J Hepato-Biliary-Pancreat Surg. 2006:13(3):207-11.

2. Lermite E, Sommacale D, Piardi T, Arnaud J-P, Sauvanet A, Dejong CHC, Pessaux P. Complications after pancreatic resection: diagnosis, prevention and management. Clin Res Hepatol Gastroenterol. 2013;37(3):230-9.

3. Kawai $\mathrm{M}$, Yamaue $\mathrm{H}$. Analysis of clinical trials evaluating complications after pancreaticoduodenectomy: a new era of pancreatic surgery. Surg Today. 2010;40(11):1011-7.

4. Grobmyer SR, Pieracci FM, Allen PJ, Brennan MF, Jaques DP. Defining morbidity after pancreaticoduodenectomy: use of a prospective complication grading system. J Am Coll Surg. 2007;204(3):356-64.

5. Machado MC, da Cunha JE, Bacchella T, Bove P. A modified technique for the reconstruction of the alimentary tract after pancreatoduodenectomy. Surg Gynecol Obstet. 1976;143(2):271-2.

6. Ke S, Ding X-M, Gao J, Zhao A-M, Deng G-Y, Ma R-L, Xin Z-H, Ning C-M, Sun $W$-B. A prospective, randomized trial of rouX-en-Y reconstruction with isolated pancreatic drainage versus conventional loop reconstruction after pancreaticoduodenectomy. Surgery. 2013;153(6):743-52.

7. Murakami $Y$, Uemura $K$, Sudo T, Hayashidani Y, Hashimoto $Y$, Nakagawa N, Ohge $H$, Sueda T. An antecolic roux-en $Y$ type reconstruction decreased delayed gastric emptying after pylorus-preserving pancreatoduodenectomy. J Gastrointest Surg. 2008;12(6):1081-6.

8. Sakamoto Y, Yamamoto Y, Hata S, Nara S, Esaki M, Sano T, Shimada K, Kosuge T. Analysis of risk factors for delayed gastric emptying (DGE) after 387 pancreaticoduodenectomies with usage of 70 stapled reconstructions. J Gastrointest Surg. 2011;15(10):1789-97.

9. Busquets J, Martín S, Fabregat J, Secanella L, Pelaez N, Ramos E. Randomized trial of two types of gastrojejunostomy after pancreatoduodenectomy and risk of delayed gastric emptying (PAUDA trial). Br J Surg. 2019:106(1):46-54

10. Aghalarov I, Herzog T, Uhl W, Belyaev O. A modified single-loop reconstruction after pancreaticoduodenectomy reduces severity of postoperative pancreatic fistula in high-risk patients. HPB. 2018;20(7):676-83.

11. Ben-Ishay O, Zhaya RA, Kluger Y. Dual loop (roux en Y) reconstruction with isolated gastric limb reduces delayed gastric emptying after pancreaticoduodenectomy. World J Gastrointest Surg. 2019;11(2):93-100.

12. Kaman L, Sanyal S, Behera A, Singh R, Katariya RN. Isolated roux loop pancreaticojejunostomy vs single loop pancreaticojejunostomy after pancreaticoduodenectomy. Int J Surg (London, England). 2008;6(4):306-10.

13. Bassi C, Dervenis C, Butturini G, Fingerhut A, Yeo C, Izbicki J, Neoptolemos J, Sarr M, Traverso W, Buchler M. Postoperative pancreatic fistula: an international study group (ISGPF) definition. Surgery. 2005;138(1):8-13.

14. Wente MN, Bassi C, Dervenis C, Fingerhut A, Gouma DJ, Izbicki JR, Neoptolemos JP, Padbury RT, Sarr MG, Traverso LW, et al. Delayed gastric emptying (DGE) after pancreatic surgery: a suggested definition by the international study Group of Pancreatic Surgery (ISGPS). Surgery. 2007; 142(5):761-8.

15. Dindo D, Demartines N, Clavien PA. Classification of surgical complications: a new proposal with evaluation in a cohort of 6336 patients and results of a survey. Ann Surg. 2004;240(2):205-13.

16. GA Wells BS, D O'Connell, J Peterson, V Welch, M Losos, P Tugwell: The Newcastle-Ottawa Scale (NOS) for assessing the quality of nonrandomized studies in meta-analyses. 2015. http://www.ohrica/programs/clinical_ epidemiology/oxfordasp.

17. Egger M, Davey Smith G, Schneider M, Minder C. Bias in meta-analysis detected by a simple, graphical test. BMJ. 1997;315(7109):629-34.

18. Cameron AC, Trivedi PK. Microeconometrics; 2012.

19. Ballas K, Symeonidis N, Rafailidis S, Pavlidis T, Marakis G, Mavroudis N, Sakantamis A. Use of isolated roux loop for pancreaticojejunostomy reconstruction after pancreaticoduodenectomy. World J Gastroenterol. 2010; 16(25):3178-82.
20. Chhaidar A, Mabrouk MB, Ali AB. Isolated roux loop pancreaticojejunostomy versus conventional pancreaticojejunostomy after pancreaticoduodenectomy: a case-control study. Int J Surg Case Rep. 2018; 53:223-7.

21. Li DB, Chai C, Cao L, Zhou YM. Isolated roux-en-Y reconstruction versus conventional reconstruction after pancreaticoduodenectomy. Surgeon. 2017;15(1):18-23.

22. Perwaiz A, Singhal D, Singh A, Chaudhary A. Is isolated roux loop pancreaticojejunostomy superior to conventional reconstruction in pancreaticoduodenectomy? HPB (Oxford). 2009;11(4):326-31.

23. Shimoda M, Kubota K, Katoh M, Kita J. Effect of billroth II or roux-en-Y reconstruction for the gastrojejunostomy on delayed gastric emptying after pancreaticoduodenectomy: a randomized controlled study. Ann Surg. 2013; 257(5):938-42.

24. Tani M, Kawai M, Hirono S, Okada Kl, Miyazawa M, Shimizu A, Kitahata Y, Yamaue $H$. Randomized clinical trial of isolated roux-en-Y versus conventional reconstruction after pancreaticoduodenectomy. Br J Surg. 2014;101(9):1084-91.

25. Mohamed El-Sorogy TA, El-Ebidy G, Tarek Salah MD. Evaluation of the Different Methods of Pancreatic Reconstruction after Pancreaticoduodenectomy. A Prospective Randomized Study. Med J Cairo Univ. 2016:84(1):9.

26. Grobmyer SR, Hollenbeck ST, Jaques DP, Jarnagin WR, DeMatteo R, Coit DG, Blumgart LH, Brennan MF, Fong Y. Roux-en-Y reconstruction after pancreaticoduodenectomy. Arch Surg (Chicago, III : 1960). 2008;143(12): 1184-8

27. Casadei R, Zanini N, Pezzilli R, Calculli L, Ricci C, Antonacci N, Minni F. Reconstruction after pancreaticoduodenectomy: isolated roux loop pancreatic anastomosis. Chir Ital. 2008;60(5):641-9.

28. Suc B, Msika S, Fingerhut A, Fourtanier G, Hay J-M, Holmières F, Sastre B, Fagniez P-L, French Associations for Surgical R. Temporary fibrin glue occlusion of the main pancreatic duct in the prevention of intra-abdominal complications after pancreatic resection: prospective randomized trial. Ann Surg. 2003;237(1):57-65.

29. Xiong JJ, Altaf K, Mukherjee R, Huang W, Hu WM, Li A, Ke NW, Liu XB. Systematic review and meta-analysis of outcomes after intraoperative pancreatic duct stent placement during pancreaticoduodenectomy. $\mathrm{Br}$ J Surg. 2012;99(8):1050-61.

30. Berger AC, Howard TJ, Kennedy EP, Sauter PK, Bower-Cherry M, Dutkevitch S, Hyslop T, Schmidt CM, Rosato EL, Lavu H, et al. Does type of pancreaticojejunostomy after pancreaticoduodenectomy decrease rate of pancreatic fistula? A randomized, prospective, dual-institution trial. J Am Coll Surg. 2009;208(5):738-49.

31. Singhal D, Goyal N, Gupta S, Soin AS, Nundy S. Isolated loop pancreatic remnant drainage following pancreaticoduodenal resection. Hepatogastroenterology. 2008;55(82-83):677-80.

32. Toogood GJ, Wilson TG, Padbury RT. A modification of isolated roux loop reconstruction after pancreaticoduodenectomy. Aust N Z J Surg. 1999:69(5): 363-4.

33. Malleo G, Vollmer CM Jr. Postpancreatectomy complications and management. Surg Clin North Am. 2016;96(6):1313-36.

34. Yang J, Wang C, Huang Q. Effect of Billroth II or roux-en-Y reconstruction for the Gastrojejunostomy after Pancreaticoduodenectomy: meta-analysis of randomized controlled trials. J Gastrointest Surg. 2015;19(5):955-63.

\section{Publisher's Note}

Springer Nature remains neutral with regard to jurisdictional claims in published maps and institutional affiliations. 